\title{
COMO CONCILIAR HUMANIZAÇÃO E TECNOLOGIA NA FORMAÇÃO DE ENFERMEIRAS/OS?'
}

\author{
HOW TO CONCILIATE HUMANIZATION AND TECHNOLOGY IN THE EDUCATION OF NURSING \\ PROFESSIONALS?
}

\author{
¿CÓMO CONCILIAR HUMANIZACIÓN Y TECNOLOGÍA EN LA FORMACIÓN DE \\ ENFERMERAS/OS?
}

Dagmar Estermann Meyer²

RESUMO: O artigo discute a incorporação do tema da humanização do cuidado no contexto da Enfermagem brasileira, na atualidade. Dentre as muitas possibilidades de se abordar este tema, optou-se por problematizar a relação Enfermagemtecnologia em uma perspectiva histórica, para então desenvolver a proposição da "ressignificação do humano" tomando como referência o conceito de ciborgue, tal como este vem sendo desenvolvido pela teorização feminista e cultural contemporânea.

PALAVRAS-CHAVE: estudos feministas, estudos culturais, humanização do cuidado, enfermagem, tecnologia

ABSTRACT: This paper discusses the current incorporation of the subject of humanization of care in the current context of Brazilian nursing. The relation between nursing and technology is approached, in this study, from a historical perspective. The study also develops the proposition of "human re-signification", having as reference the concept of Cyborg, considering the way this concept has been employed in the contemporary cultural and feminist theoretical framework.

KEYWORDS: feminist studies, cultural studies, humanization of care, nursing, technology

RESUMEN: El artículo discute la incorporación del tema de la humanización del cuidado en el contexto de la Enfermería brasileña de la actualidad. Entre las muchas posibilidades de abordar este tema se ha optado por problematizar la relación Enfermeria-Tecnología dentro de una perspectiva histórica, para entonces desarrollar la proposición de la "resignificación de lo humano" y tomar como referencia el concepto de "cyborg", tal como se ha venido desarrollando por la teorización feminista y cultural contemporánea.

PALABRAS CLAVE: estudios feministas, estudios culturales, humanización del cuidado, enfermería, tecnología

Recebido em 26/02/2002

Aprovado em 26/06/2002

\footnotetext{
1 Versão modificada de Conferência proferida na abertura da IV Jornada Sul Riograndense de Saúde da Mulher e do Neonato, realizada em Porto Alegre/RS, no periodo de 5 a 7 de agosto de 2001.

2 Enfermeira. Doutora em Educação pela Universidade Federal do Rio Grande do Sul. Professora adjunta na Faculdade de Educação, em nivel de graduação e pós-graduação; pesquisadora e atual coordenadora do Grupo de Estudos de Educação e Relações de Gênero, na mesma instituição.
} 


\section{UMA PERGUNTA E SEUS DESDOBRAMENTOS}

Este texto foi escrito, tomando como referência uma questão que me foi proposta pela ABENFO/RS, para que eu a desenvolvesse na abertura do seminário estadual que essa entidade promoveu em agosto de 2001. Dentre as muitas possibilidades que tinha para abordar a temática da humanização - tão candente no contexto da Enfermagem contemporânea - acabei optando por problematizar, primeiramente, a pergunta - título que me foi proposta, para depois trabalhar a proposição de ressignificar o humano no contexto da ciborguização, a qual, em minha perspectiva, seria uma resposta possivel à questão então formulada.

Quero justificar essa opção, a partir da explicitação de dois pressupostos teórico-metodológicos que, em linhas gerais, têm norteado minhas atividades de formação e de pesquisa, na última década. O primeiro deles está inscrito em uma perspectiva onde se entende que o conhecimento e as práticas sociais a ele vinculadas são construções discursivas, resultantes e/ou geradoras de relações de poder, cujo produto (a verdade sobre a Enfermagem, o cuidado humanizado, o processo saúde/doença, o eu saudável e/ou o outro doente, por exemplo) está circunscrito ao espaço daquilo que é possivel em um dado contexto histórico, social, cultural e lingüistico. Ou seja, trabalha-se, aí, com o pressuposto de que nada é "natural", nada está dado de antemão, toda verdade é parcial e provisória e resulta de disputas travadas em diversos âmbitos do social e pode, por isso, ser problematizada. O segundo pressuposto me leva a assumir a posição de que as perguntas que fazemos são sempre interessadas e, por vezes, mais importantes do que as possiveis respostas que construímos para elas. Perguntas são sempre feitas por alguém (sujeito individual e/ou coletivo), que só começa e/ou consegue formulá-las de um determinado modo, a partir de um lugar (instituições, referenciais teóricos, projetos políticos, dificuldades, sonhos e frustrações) e em um tempo específicos. Nessa perspectiva, as perguntas só importam e fazem sentido nesse contexto e, às vezes, são as dúvidas que temos que nos levam a estes "lugares" particulares e, outras vezes, são estes lugares que ocupamos que acabam por transformar determinados aspectos do cotidiano em dúvidas ou problemas.

O título deste artigo me foi, originalmente, apresentado como uma pergunta: Como conciliar humanização e tecnologia na formação de enfermeiras/os? Ao me debruçar sobre ele, e considerando exatamente os pressupostos apresentados acima, quatro novas perguntas me ocorreram antes que eu pudesse pensar em possiveis respostas para essa indagação: o que se está entendendo por humanização e por tecnologia quando se formula essa pergunta? Em que humanização e tecnologia diferem e por que se sugere, com o uso do termo conciliar, que elas se opõem? O que faz com que essa pergunta seja importante para a Enfermagem, hoje? Como os referenciais teóricos dos Estudos Feministas e dos Estudos Culturais - com que venho trabalhando, poderiam contribuir para essa discussão? Tomo, então, essas perguntas, não necessariamente nessa ordem, como referência e como limites para este texto, pontuando que minha abordagem se insere em uma de muitas outras perspectivas que, atualmente, permitem discutir essas questões. Com essa abordagem, a minha intenção é a de compartilhar idéias e contribuir para o debate, sem nenhuma pretensão de, com ela, estar apresentando a única (ou a melhor) forma para se pensar a humanização, no contexto da Enfermagem brasileira contemporânea.

\section{A RELAÇÃO ENFERMAGEM-TECNOLOGIA: UM OLHAR SOBRE O HOJE}

Começo, então, focalizando um pouco as relações entre Enfermagem e tecnologia. Por que o debate em torno dessa relação importa? O que está em jogo quando se faz essa discussão?

Os autores e as autoras que trabalham com essa temática são incansáveis em apontar para a complexidade e a multiplicidade de definições possiveis para tecnologia. Elisabeta Nietsche ${ }^{3}$ (2000), por exemplo, em uma extensa revisão dos sentidos passiveis de serem atribuidos ao termo, afirma que quando enfermeiras falam ou pensam em tecnologia no seu cotidiano profissional estão, geralmente, pensando em um produto ou artefato material usado para facilitar ou tornar mais eficientes as tarefas diárias e, o que é mais comum ainda, associam o termo à informatização, à cibernética, à robótica, enfim, aos produtos da chamada biotecnologia de ponta. Da mesma forma, um estudo desenvolvido por enfermeiros australianos para investigar concepções de tecnologia vigentes entre enfermeiras médicocirúrgicas em Queensland (BARNARD; GERBER, 1999) referenda essa afirmação, quando aponta que a tecnologia é definida e experienciada, fundamentalmente, como maquinaria e equipamentos. Ou seja, faz-se referência, mais comumente, à dimensão física ou material da tecnologia. Quando esses pesquisadores procuraram explorar essa concepção, tomando como referência a relação enfermeira-usuário do serviço - exatamente o que me parece estar em jogo quando se coloca o debate que contrapõe humanização à tecnologia - essa concepção mais genérica e superficial foi sendo desdobrada pelos sujeitos do estudo em categorias que, a meu ver, podem ser agrupadas em dois grandes grupos.

Um que celebra e, portanto, define a tecnologia como sendo boa para o desenvolvimento da Enfermagem. Nessa perspectiva, fala-se que a tecnologia fornece meios e condições para avaliar procedimentos, técnicas ou instrumentos já existentes, subsidiando o desenvolvimento de novos; a tecnologia seria uma instância através da qual se incrementa o conhecimento de Enfermagem e se potencializa o grau de controle sobre a prática assistencial, no sentido de torná-la mais exata, mais eficaz e mais eficiente. A utilização e o desenvolvimento de tecnologia implicaria, portanto, em mais tempo e melhores condições

\footnotetext{
${ }^{3}$ Escrever por extenso o nome dos autores e autoras - quando este é inserido pela primeira vez no texto propriamente dito - contraria as normas de redação científica propostas pela ABNT. Esta, no entanto, é uma opção política, decorrente de minha inserção no Campo dos Estudos Feministas, que visa tornar visiveis (quando não é possivel fazê-lo de outro modo) mulheres e homens que produzem os textos com que trabalhamos.
} 
para qualificar a relação enfermeira-usuário e, ainda, em aumento do reconhecimento social e da autonomia profissional da enfermeira.

O segundo grupo faz uma avaliação pessimista da relação Enfermagem-tecnologia. Entende-se, no contexto dessas manifestações, que a tecnologia prejudica, deforma ou impede a relação enfermeira-usuário, nos termos em que esta vem sendo definida pelas teorias de Enfermagem vigentes. Nessa perspectiva, a tecnologia é definida e experienciada como barreira nessa relação. A tecnologia é significada como intensificação do trabalho, como um mecanismo que coloca o manuseio e o controle de drogas, máquinas e equipamentos cada vez mais complexos (e perigosos!) no centro da atenção da Enfermagem. A utilização e o desenvolvimento tecnológico, portanto, levaria as enfermeiras a desenvolverem uma prática excessivamente centrada no diagnóstico e na intervenção, na qual o ser humano é traduzido apenas como informação (gerada pelos exames cada vez mais sofisticados e pela infinidade de telas e monitores que qualificam, quantificam e visibilizam suas funções biofisiológicas).

Um terceiro e não muito significativo grupo de manifestações poderia ser enquadrado naquilo que eu, particularmente, chamaria de uma relação mais cautelosa, mas, ainda assim, descontextualizada, com a tecnologia. Nessa perspectiva, enfatiza-se que a tecnologia, traduzida como máquinas ou equipamentos, não é boa ou má per se, que o resultado ou o impacto do seu uso se define em estreita relação com o contexto físico, material e social do cuidado. Aqui, a tecnologia é entendida como sendo contextodependente, ou seja, o contexto e a cuidadora são modificados pela tecnologia ao mesmo tempo em que a modificam também. O problema, nesta abordagem, é que o termo contexto é tomado em sentido estrito, como local e condições de trabalho e não como condições sociais, históricas e políticas que produzem a relação Enfermagemtecnologia de determinados modos e não de outros.

Eu me detive em abordar ${ }^{4}$ este estudo, de forma mais extensiva, porque penso, em primeiro lugar, que os três grupos de categorias descrevem experiências/situações vivenciadas pela Enfermagem em sua relação com a tecnologia, ou seja, tais percepções não são excludentes entre si, embora possam ser vividas ou concebidas de tal forma. Em segundo lugar, penso que tal estudo sintetiza concepções de tecnologia também vigentes na Enfermagem brasileira. Por último, acredito que são polaridades como as que se estabelecem entre celebração e contestação, entre uma tecnologia representada como intrinsecamente boa ou má, entre ser humano e máquina como sendo instâncias distintas e estritamente separadas, entre curar/tratar e cuidar, entre masculino e feminino e entre razão e emoção, que estão em jogo e modulam esse debate em torno da necessidade de conciliar humanização e tecnologia na formação de enfermeiras. Apesar de elas estarem subjacentes e modelarem as concepções apresentadas nesse e em outros estudos desenvolvidos em torno desse tema, chamou-me a atenção que tais polaridades não são reconhecidas e nomeadas pelas enfermeiras investigadas.
Por extensão, os seus efeitos sobre a relação Enfermagem - tecnologia são pouco articulados com a trajetória histórica, social e cultural da Enfermagem, nos paises ocidentais. Vou, então, me ater brevemente a alguns aspectos dessa trajetória, porque isso pode ser bastante útil para situar e contextualizar algumas dessas polaridades.

\section{A RELAÇÃO ENFERMAGEM-TECNOLOGIA: UM OLHAR SOBRE O ONTEM}

Ao contrário do que a ênfase nas hoje chamadas tecnologias de ponta sugere, a tecnologia definida em um sentido mais amplo, ou seja, "como conhecimentos e instrumentos que, interligados, fundamentam e delimitam modos sistematizados de fazer e de cuidar", está intimamente relacionada com a Enfermagem profissional desde sua emergência no final do séc. XIX. As enfermeiras profissionais, desde o início, buscaram suporte em variados campos do conhecimento para apoiar o emprego de uma variedade de instrumentos e de procedimentos, que hoje talvez não reconheçamos mais tão facilmente como artefatos tecnológicos, para avaliar, intervir e confortar seres humanos com problemas de saúde ou que estavam vivendo momentos particulares do seu ciclo vital (gestação, nascimento, primeira infância, velhice ou morte, etc). Pode-se citar, por exemplo: determinados modos de dispor as pessoas no espaço, formas adequadas de aproveitamento da luz e de canalização do ar, camas diferenciadas, bombas de infusão, comadres, jarros, termômetros até chegarmos aos monitores e ventiladores contemporâneos.

A Enfermagem profissional também foi definida, desde o início, como uma profissão feminina, cujo fazer estava centrado no cuidar, em oposição ao tratar que caracterizava a Medicina Científica, a qual também se organizava no mesmo período, e que era representada como profissão masculina. Tratar e cuidar, masculino e feminino e, por extensão, Medicina Científica e Enfermagem são, pois, oposições constitutivas da Enfermagem moderna. Se, por um lado, podemos dizer que a oposição do cuidar ao tratar pretendia permitir a diferenciação da Enfermagem em relação à Medicina, no processo de legitimação e de construção de um campo de saber/fazer específicos na área da saúde, podemos, por outro lado, dizer também que a introdução, o uso e o desenvolvimento de tecnologias cientificamente legitimadas foi uma das dimensões que diferenciou a Enfermagem das práticas leigas e religiosas que até então caracterizavam o cuidado no processo saúde/doença. Assim, a tecnologia contribuiu para conferir a esta prática social apresentada como um trabalho de mulheres voltado para o cuidado sistematizado - o estatuto de profissão socialmente reconhecida e regulada, com exigências especificas de formação.

Nesse processo de profissionalização da Enfermagem buscou-se, também desde o início, construir um campo de conhecimentos específicos que deveria tanto manter operantes os sistemas de valores que caracterizavam o feminino e o cuidado como sua extensão, quanto adquirir o estatuto de ciência. E o que podemos ver nesse processo,

\footnotetext{
${ }^{4}$ A tradução do texto e o agrupamento das categorias nos grupos aqui elencados é de minha inteira responsabilidade.
} 
genericamente falando, é que a relação com a tecnologia, definida e valorada como tributária do paradigma positivista de ciência, foi entendida e experienciada, hegemonicamente, de duas formas distintas. (RUDGE, 1999, SANDELOWSKI, 1999, FAIRMAN; D'ANTONIO, 1999).

De maneira sintetizada, poderiamos descrever um primeiro longo momento, que se estende mais ou menos até os anos sessenta do século XX, em que a tecnologia foi incorporada como uma dimensão fundamental da profissionalização: conhecer, dominar, manusear e desenvolver tecnologia era um imperativo da cientifização. A luta pelo acesso ao estatuto dominante de ciência não incluiu, nesse periodo, o questionamento do que era definido, nas sociedades ocidentais modernas, como ciência e conhecimento científico. O movimento que se fez foi o de assumir, como seus, os pressupostos filosóficos modernos ou iluministas que fundamentavam tal paradigma: a universalidade, a racionalidade, a neutralidade, a objetividade, a prerrogativa de definir a verdade, a ascendência sobre qualquer outra forma de saber que não compartilhasse de tais requisitos, a suposição de uma essência de humano centrada na razão, dentre muitos outros.

Em um segundo momento, que se vive e se agudiza à medida que se ampliam as críticas a esses pressupostos filosóficos da modernidade ocidental, a pretensa neutralidade e universalidade deste paradigma passam a ser colocadas em questão. Ele passa a ser teorizado, sobretudo pelas estudiosas da chamada segunda onda feminista, como sendo o paradigma de uma ciência produzida dentro de uma visão de mundo masculina, branca, burguesa e judaico-cristã. Nesse contexto, o desejo e a necessidade crescentes da Enfermagem de diferenciar-se das outras profissões no campo da saúde, em particular da Medicina, levou a uma ressignificação da relação com a tecnologia. Exatamente porque passa a ser entendida como sendo uma dimensão (ou um desdobramento) dessa racionalidade científica - agora teorizada como androcêntrica - a tecnologia, a quem se vem também atribuindo cada vez mais a responsabilidade por uma gama de "erros" ou de malversações do tratar e do cuidar, passa a ser representada como a força desumanizante tanto dos cuidadores e cuidadoras quanto dos seres humanos que demandam cuidados.

Os estudos das autoras acima citadas me permitem dizer que, no que se refere às relações Enfermagemtecnologia, a primeira (definida como vocação, ciência e arte) procurou teorizar o cuidar, em contraposição ao tratar, de duas formas distintas e complementares. No primeiro momento, onde se buscava a legitimação pela cientifização, conciliar a objetividade da ciência masculina com a intuitividade e a emoção que caracterizavam o feminino, posicionava o cuidado como interface de humanização na relação médico-paciente. No segundo momento, com a ilimitada possibilidade de tecnologização de todas as dimensões do processo saúde-doença e com as críticas ao paradigma de ciência que ainda sustenta, em grande parte, essa tecnologização, o cuidado, que estaria fundado no ceme de uma cultura feminina, vem sendo teorizado, crescentemente, como a interface de humanização nessa relação tecnologia-cliente que ai se processa.

$\mathrm{O}$ que estas duas abordagens (aqui bastante simplificadas) nos permitem perceber é que todas as problematizações empreendidas no âmbito profissional até aqui, parecem ter deixado intocadas, em ambos os casos, as noções de humanização e de humano e, por extensão, de masculino e feminino que sustentam as teorizações acerca do cuidado. As fronteiras que definem a humanidade do ser parecem não ter sido colocadas em questão.

\section{HUMANO, CORPO E MÁQUINA: TRÊS TERMOS EM TENSÃO}

O que é que tem sido entendido como humano, no contexto de discussões como essa da humanização? Como já apontei em trabalho anterior (MEYER, 2001), no campo filosófico, o humano tem sido narrado como alguma modalidade de reflexividade da pessoa consigo mesma desde tempos muito remotos. Jorge Larrosa (1994, p. 39), no entanto, indica que "a reflexividade [ordenada pela razão] só obtém uma certa centralidade antropológica na filosofia moderna", inaugurada por Bacon e, principalmente por Descartes, com o cogito "Penso, logo existo" a partir do qual se elabora a idéia de que "a pessoa humana [...] existe de maneira que pode adotar uma relação cogniscitiva e prática com sua própria existência, de maneira que tenha uma determinada interpretação de quem é e do que pode fazer consigo mesma".

Entra em ação, aqui, a noção de sujeito inaugurada pelo lluminismo. Também chamado de sujeito cartesiano ou sujeito humanista ele é concebido como sendo capaz de ser (ou de se tornar) totalmente autônomo, livre, autoconsciente e coerente, e seu centro ou essência reside em um núcleo interior que o constitui desde que nasce e que com ele se desenvolve, num movimento de aperfeiçoamento contínuo, ao longo de sua existência. Esse centro, tomado como origem da racionalidade, da consciência e do conhecimento, constitui, nessa perspectiva, o humano que o qualifica como sujeito. Ele é também posicionado como o centro do mundo, o único ser vivo não só capaz mas autorizado a agir sobre a natureza e sobre todos os outros seres vivos, para produzir conhecimento e qualificar o seu modo de vida.

Essa definição de ser humano que nos parece hoje tão familiar, natural e evidente é, no entanto, contingente, cultural e histórica; ou seja, ela não tem nada de natural e de auto-evidente e temos sido confrontadas com essa problematização desde a emergência da psicanálise freudiana e seus desdobramentos lacanianos, passando pelo estruturalismo e adentrando por todas as teorizações "pós". O que estas teorizações têm enfatizado, de diferentes modos, é que o sujeito e, portanto o humano do sujeito, "não existem fora da história e da linguagem, fora da cultura e das relações de poder" (SILVA, 2000, p.12). Elas enfatizam, em sintese, que esta noção de sujeito não se sustenta mais e que ela precisa ser ressignificada.

Mas esse sujeito humanista, definido por uma essência que reside na razão, foi desnudado pelas feministas que apontaram suas especificidades: europeu, masculino, branco, burguês e cristão, produzido no âmbito da mesma episteme que representou a mulher como o Outro da razão. A mesma episteme que não só separou, mas subordinou a natureza à cultura e a transformou em objeto de conhecimento. Nesse processo, também o corpo foi separado 
da razão - a substância que nos define como humanos - e este corpo, inscrito no domínio da natureza, constituiu-se, paradoxalmente, em objeto de conhecimento e da vontade dessa mesma razão que, supostamente, o habita.

Assim, a essência do humano, que já era representada no pensamento religioso judaico-cristão como uma alma ou espírito transcendente e imortal e que foi redefinida no âmbito da filosofia iluminista como razão, continuou colocada fora do corpo. Esse corpo que, entendido e tratado como objeto da ciência cartesiana e de seus desdobramentos tecnológicos, foi sendo, desde então, minuciosamente retalhado, explorado e descrito, para ser conhecido, dominado e transformado. Laymert Garcia dos Santos (2001, p.10) diz que, nesse processo de descobrimento e colonização do corpo, este passou, gradativamente, a ser concebido como uma ordem de dados visuais, numa operação onde " a vida é teorizada cada vez mais como um conjunto de informações e o organismo humano é lido como um conjunto de códigos. Uma operação que deixa o "humano" aberto a múltiplas incursões. Como constata Tomaz Tadeu da Silva (2000, p. 12) é, justamente, "no confronto com clones, ciborgues e outros hibridos tecnoculturais que a 'humanidade' de nossa subjetividade se vê colocada em questão".

Assim, é no mesmo movimento em que se dissolvem as fronteiras entre natureza e cultura e entre o corpo (dado por essa natureza) e a máquina (um artefato tecnológico dessa cultura) que noções transcendentais de humano e de humanização passam a ser acionadas com um renovado vigor, na área da saúde e, em especial, da Enfermagem. Caberia, no entanto, perguntar-se: a noção de uma humanidade essencial e original, representada agora como mais próxima do feminino, absolutamente diferente e separada da tecnologia, representada agora como masculina, ainda se sustenta? A que ela serve? Onde termina, hoje, o humano do corpo e começa a máquina? Ou, talvez fosse melhor inverter a pergunta, sobretudo na área da saúde: onde termina a máquina e começa o humano? Ou, será que ainda sabemos ou podemos cuidar do humano sem a interposição da máquina? Ainda poderiamos ser as enfermeiras que somos e promover os cuidados que prescrevemos se nos desconectarmos das máquinas e equipamentos e deixarmos de implementar a multiplicidade de procedimentos e técnicas tecnologicamente fundamentadas que povoam e configuram nossos ambientes de trabalho? Ou, como continua provocando Silva (2000, p. 13):

Não seria o caso de se considerar [essas] perguntas sem sentido? Mais do que a metáfora, é a realidade do ciborgue, sua inegável presença em nosso meio, que põe em xeque a ontologia do humano. Ironicamente, a existência do ciborgue não nos intima a perguntar sobre a natureza das máquinas, mas, muito mais perigosamente, sobre a natureza do humano: quem somos nós?

\section{HUMANO-MÁQUINA: FRONTEIRAS MÓVEIS E ESVAECIDAS}

Donna Haraway (2000) é uma das teóricas feministas contemporâneas que defende o argumento da onipresença do ciborgue nas culturas contemporâneas. O ciborgue é um híbrido humano/máquina e, como todo híbrido que resulta da fusão de entes de natureza diversa, não pode mais ser reduzido ou reconduzido a nenhuma humanidade, natureza ou tecnologia original. Em perspectivas teóricas como essa, estariamos hoje mergulhados em processos de ciborguização, alguns dos quais, como acionar o interruptor de luz e passar a enxergar no escuro, por exemplo, estão tão incorporados e banalizados em nosso cotidiano que nem os reconhecemos mais como tais.

Segundo Chris Gray, Steven Mentor e Heidi FigueroaSarriera citados por SILVA (2000, p. 14) os processos de ciborguização podem ser de diferentes tipos e ilustrá-los rapidamente com exemplos de nosso cotidiano, pode nos ajudar a perceber melhor o quanto eles estão arraigados em nossas vidas. Os processos de ciborguização podem ser, então: 1) restauradores, quando restauram funções (a visão com o uso dos óculos), ou substituem órgãos ou membros perdidos (os marcapassos ou as próteses mais diversas); 2) normalizadores, quando retornam as criaturas a uma indiferente normalidade (com o uso de anti-depressivos, analgésicos ou antitérmicos ou, ainda, através de cirurgias plásticas reparadoras); 3) reconfiguradores, quando criam criaturas pós-humanas que são iguais aos seres humanos e, ao mesmo tempo, diferentes deles (todas as crianças que tomam o conjunto de vacinas prescritas pelo programa de assistência à saúde da criança, as quais reconfiguram o seu sistema imunológico de tal forma que elas passam a ter imunidade a doenças às quais estariam expostas se mantivessem o seu sistema imunológico "natural", ou em um outro nivel, as cirurgias para mudança de sexo); 4) melhoradores quando criam criaturas melhoradas relativamente ao ser humano "natural ou original" (todas as formas de alimentação balanceada ou enriquecida com vitaminas e sais minerais, as cirurgias plásticas estéticas, os programas de condicionamento físico, para ficar nas coisas mais simples).

$\mathrm{Se}$, aqui, eu me ative a citar exemplos nos quais seres vivos se tornam, em graus mais ou menos intensos, artificiais, é preciso não esquecer que a ciborguização se processa dos dois lados da fronteira, criando também seres que não apenas simulam características dos humanos, mas se apresentam melhorados em relação a esses últimos (os computadores com memórias cada vez mais potentes, os ventiladores mecânicos cada vez mais sensiveis e precisos, dentre outros). São, exatamente, essas tecnologias que simulam o humano, ou que tornam possivel a produção de seres vivos cada vez mais aperfeiçoados, que assombram os nossos tempos atuais: as tecnologias reprodutivas, a manipulação genética, a clonagem, as mudanças de sexo, a robotização. E aqui reside um dos aspectos mais aterrorizantes dos tempos em que vivemos: essas tecnologias não apenas colocam em dúvida a origem divina do humano - um movimento que foi feito com a instauração da modernidade - mas colocam em xeque, isto sim, "a origininalidade do humano" (SILVA, 2000, p.16).

A capa de um dos números da Revista Super Interessante é emblemática nesse sentido, quando apresenta, em manchete, o filme Inteligência Artificial - "A nova superprodução de Steven Spielberg chega às telas e faz o mundo todo se perguntar: o que vai acontecer conosco quando as máquinas não precisarem mais dos seres 
humanos?" (julho de 2001). A relação promíscua e cada vez mais inevitável com a tecnologia foi também tema de um seminário sobre Ética e genética, em Porto Alegre, em agosto de 2001. Excertos da fala de dois dos palestrantes desse evento, um geneticista e outro filósofo, são bastante provocativos para a reflexão que faço neste artigo. Referindose ao contexto tecnologizado atual, diz o geneticista: "os organismos [vivos e artificiais] ao nosso redor não são mais subalternos, mas companheiros de jornada"(ERDTMANN, 2001, p. 4). Afirma o filósofo: "a nova biologia genética altera nosso velho conceito de humano" (STEIN, 2001, p. 5).

Diante de tudo isso, fico me perguntando se a questão de como conciliar humanização e tecnologia não contém um falso dilema, uma vez que o ciborgue é uma expressão concreta e material dessa conciliação. Talvez não importe mais, também, discutir se somos a favor ou contra a tecnologização, da vida em geral e da saúde em particular, uma vez que já somos (ou estamos) todos afetados por esse processo. Situados no centro, na periferia ou do lado de fora de suas fronteiras, somos todos afetados por ele: o degelo das calotas polares, o buraco na camada de ozônio, a poluição do ar e da água, a chuva ácida, o desmatamento e a conseqüente desertificação de terras férteis são efeitos neste caso negativos porque atentam contra a sobrevivência do próprio planeta - que atingem indistintamente todos os seres vivos.

Não se trata, aqui, também, de fazer uma apologia acrítica da tecnologia, mas de reconhecer a sua inevitabilidade. Como lidar com isso? Haraway, citada por Hari Kunzru (2000), argumenta que a tecnologia não é neutra. Que estamos dentro daquilo que fazemos e que aquilo que fazemos está dentro de nós e, ainda, que vivemos em um mundo de conexões. E que nesse mundo de conexões é importante saber quem é que é feito e quem é que é desfeito. Nessa perspectiva, Santos (2001), por exemplo, nos instiga a perguntar: quais têm sido, historicamente, os corpos dos quais se extraem as informações que alimentam as tecnologias destinadas a melhorar a qualidade de vida de outros seres vivos? Ao que eu acrescentaria: Quem é que está situado no centro das tecno-culturas que habitamos e quem é que está nas suas margens? Com que efeitos? Mais do que epistemológicas estas dimensões da relação entre humano e máquina são, fundamentalmente, questões políticas.

\section{RESSIGNIFICAR O HUMANO NO CONTEXTO DA CIBORGUIZAÇÃO: UMA PROPOSIÇÃO}

Quero finalizar pontuando que penso que as questões que a Enfermagem se coloca quando introduz essa discussão acerca da humanização são questões políticas importantes e complexas. O que não sei é se o recurso de propor o retomo a uma humanidade original e essencial, mais próxima dos assim chamados valores femininos com os quais se definem o cuidado, é a melhor saida para os dilemas políticos e éticos que a ciborguização impõe. Talvez devêssemos investir em teorizações que, ao invés de representarem a Enfermagem como interface de humanização, explorassem a potencialidade de pensar a Enfermagem como um saber/fazer ciborgue, um saber/fazer hibrido onde as fronteiras entre natureza e cultura, entre ciência e vida cotidiana, entre teoria e prática, entre masculino e feminino e entre humano e máquina fossem deslocadas de tal forma que estas oposições não pudessem mais ser acionadas para a hierarquização e a dominação. Isso poderia nos ajudar a recusar uma metafísica anticiência e uma demonização per se da tecnologia, porque ambas têm sido tanto meios de grande satisfação e qualificação da vida humana quanto, infelizmente, matrizes de grandes dominações. Esse esforço teórico e político poderia, também, nos sugerir um vocabulário, criativo e potente o suficiente, para sairmos desse labirinto de dualismos com que se tem explicado e desdobrado "o humano" em seres com estatutos sociais diferenciados, estatutos estes que têm justificado a desigualdade, a injustiça social e a subordinação.

Se voltarmos aos pressupostos que apresentei no início do texto, minha proposta talvez inclua perguntar-se em que tipo de seres humanos a linguagem do humanismo, em que fomos socializados como humanos, nos transformou. Mais do que isso, como sugere Sérgio de Oliveira (2000) ela deveria levar-nos a perguntar se o vocabulário que compõe essa linguagem humanista é o mais inclusivo possível ou se ele está promovendo dor e humilhação àqueles que não se incluem em suas descrições, embora eles sejam produzidos como outros, justamente no interior desta linguagem.

\section{REFERÊNCIAS BIBLIOGRÁFICAS}

BARNARD, A.; GERBER, R. Understanding technology in contemporary surgical nursing: a phenomenographic examination. Nursing Inquiry, volume 6, Issue 3, september 1999.

ERDTMANN, B. A polêmica da transgenia. Jornal Zero Hora, Porto Alegre, 4 de agosto de 2001.Segundo Caderno, Cultura.

FAIRMAN, J; D'ANTONIO, P. Virtual power: gendering the nursetechnology relationship. Nursing Inquiry, volume 6, Issue 3, september 1999.

HARAWAY, D. Manifesto ciborgue: ciência, tecnologia e feminismo socialista no final do século XX. In: SILVA, T. T. (Org.) Antropologia do ciborgue: as vertigens do pós-humano. Belo Horizonte: Autêntica, 2000.

KUNZRU, H. "Você é um ciborgue": um encontro com Donna Haraway. In: SILVA, T. T. (org.) Antropologia do ciborgue: as vertigens do pós-humano. Belo Horizonte: Autêntica, 2000.

LARROSA, J. Tecnologias do eu e educação. In: SILVA, T. T. (Org.) O sujeito da Educação. Estudos foucaultianos. Petrópolis: Vozes, 1994.

MEYER, D. Cuidado e diferença. Da integralidade à fragmentação do ser. Revista Gaúcha de Enfermagem, v. 22, n. 2, p. 21-38, jul. 2001.

NIETSCHE, E. Tecnologia emancipatória. Possibilidade ou impossibilidade para a práxis de Enfermagem? ljui/RS: Unijui, 2000.

OLIVEIRA, S. Gattaca: sobre o governo totalitário das identidades. Lugar Comum, n. 910, p. 175-193, 2000.

RUDGE, T. Situating wound management: technoscience, 
dressing and 'other' skins. Nursing Inquiry, volume 6, Issue 3, september 1999.

SANDELOWSKI, M. Troubling distinctions: a semiotics of the nursing/technology relationship. Nursing Inquiry, volume 6, Issue 3, september 1999.

SANTOS, L. G. O ser digital e a virada cibernética. Folha de São
Paulo, 25 de março de 2001. Caderno Mais.

SILVA, T.T. Nós, ciborgues: o corpo elétrico e a dissolução do humano. In: SILVA, T. T. (org.) Antropologia do ciborgue: as vertigens do pós-humano. Belo Horizonte: Autêntica, 2000.

STEIN, E. Existem genes para a moral? Jornal Zero Hora, Porto Alegre, 4 de agosto de 2001. Segundo Caderno, Cultura. 